\title{
Title Determinants of the Quality of Childbirth Care Along the Continuum in Limited Resource Settings: A Structural Equation Modeling Analysis of Cross- sectional Data from Burkina Faso and Côte d'Ivoire
}

Tieba Millogo ( $\square$ millogorod@gmail.com )

African Institute of Public Health

Raïssa Kadidiatou Kourouma

Cellule de Recherche en Santé de la Reproduction

Bertrand Ivlabéhiré Méda

Institut de Recherche en Sciences de la Santé

Marie Laurette Agbre-Yace

Cellule de Recherche en Santé de la Reproduction

Abdul Dosso

Cellule de Recherche en Santé de la Reproduction

Maurice W E Yaméogo

African Institute of Public Health

Seni Kouanda

Institut de Recherche en Sciences de la Santé

Research Article

Keywords: continuum of childbirth, quality of care, Burkina Faso, Côte d'Ivoire

Posted Date: July 15th, 2021

DOI: https://doi.org/10.21203/rs.3.rs-690253/v1

License: (c) (1) This work is licensed under a Creative Commons Attribution 4.0 International License.

Read Full License

Version of Record: A version of this preprint was published at BMC Pregnancy and Childbirth on December 1st, 2021. See the published version at https://doi.org/10.1186/s12884-021-04328-w. 


\section{$1 \quad \underline{\text { Title }}$}

2 Determinants of the quality of childbirth care along the continuum in limited

3 resource settings: a structural equation modeling analysis of cross-sectional

4 data from Burkina Faso and Côte d'Ivoire.

7 Tieba Millogo ${ }^{1,2, *}$, Raïssa Kadidiatou Kourouma ${ }^{3,4}$, Bertrand Ivlabéhiré Méda ${ }^{1,2}$, Marie Laurette Agbre-Yace ${ }^{3,4}$, Abdul Dosso4, Maurice W E Yaméogo ${ }^{1,2}$, Seni Kouanda ${ }^{1,2}$.

9

10

1. African Institute of Public Health (AIPH), Burkina Faso

2. Institut de Recherche en Sciences de la Santé, Burkina Faso.

3. Institut National de Santé Publique (INSP-Côte d'Ivoire)

4. Cellule de Recherche en Santé de la Reproduction, côte d'Ivoire

\section{* Corresponding author:}

African Institute of Public Health. 12 BP 199 Ouagadougou. Burkina Faso. millogorod@gmail.com ; trmillogo@iasp-bf.org.Cel:+22671910013. 


\section{Abstract}

Introduction: Despite important increase in in-facility births, perinatal mortality rates have remained high and slow to decrease in many developing countries. This situation is attributed to the poor quality of childbirth care. The reason why women delivering in health facilities do not always receive standards of care are unclear. We assessed the determinants of the quality of childbirth care along the continuum of care using different approaches.

Methods: A health facility-based cross-sectional study with a direct observation of health care workers' practices while caring for mother-newborn pairs was carried out in Burkina Faso and Côte d'Ivoire. The performance of a set of Essential Best Practices (EBPs) was assessed in each birth event at admission, pre-pushing and immediate post-partum stages. A quality score, in the form of the additive sum of EBPs effectively delivered was computed for each stage. We used negative binomial regression models and a structural equation modeling analysis to respectively assess the determinants of the quality of care at each stage and the relationships between the quality delivered at the different stages.

Results: a total of 532 and 627 mother-newborn pairs were included respectively in Burkina Faso and Côte d'Ivoire. In both countries, the quality of delivery care varies significantly at all stages between health districts. The quality of predelivery care was consistently higher in referral hospitals as compared to primary health care facilities (IRR=1.02; $p<0.05$ and IRR=1.10; $p<0.05$ respectively for Burkina Faso and Côte d'Ivoire). The quality at admission was poorer in nurses as compared to midwives in Burkina Faso $(\operatorname{IRR}=0.81 ; p<0.001)$. The quality at admission and pre-delivery stages were positively correlated with the immediate post-partum quality $(\beta=0.48 ; p<0.001$ and $\beta=0.29 ; p<0.001$ respectively). 
Conclusion: Quality improvement strategies must target both providers and health facilities

49 and different inputs are needed depending on the stage in the continuum of care.

50

Key words: continuum of childbirth, quality of care, Burkina Faso, Côte d'Ivoire

51

52

53

54

55

56

57

58

59

60

61

62

63

64

65

66

67

68 


\section{Background}

70

Timely utilization of health facilities for childbirth services has been strongly advocated for through the past two decades in low- and middle-income countries (LMIC)[1,2] where maternal and newborn death tolls remain unacceptably high despite recent improvements. This is because non-access or delay in access to proven and well-recognized effective interventions needed to prevent or adequately manage obstetrics complications were identified as major contributing factors to poor childbirth outcomes $[3,4]$. The promotion of institutional childbirths as a strategy to reduce poor maternal and newborn childbirth outcomes relies on the postulate that such interventions are readily available in health facilities and would be effectively deliver condition on the utilization of health care services. Health facility utilization alone, however, has proved not enough[5-7]. The quality of the care received by the dyad mother and newborn during the course of childbirth in the health facilities is also crucial and as facility utilization is rising, it is gradually being recognized as a missing link in the path towards ending preventable maternal and child deaths in LMIC where the quality of care is reputed most often suboptimal[8,9].In-facility morbidity and mortality outcomes depend heavily on the quality of health care received by services users as it conditions the effective delivery of the interventions that meet their health needs[10]. The quality of childbirth health care services does not only improve the medical outcomes of childbirth but is also a key factor for improving and maintaining an optimal level of services utilization. Indeed, previous studies in sub-Saharan Africa (SSA) have reported that women future decisions on whether to use or not health facilities for delivery depend on their previous use experience[11,12]. Those that were not satisfied with the services received are less likely to sustain their services utilization[13]. Because access alone is no longer sufficient, access to quality essential health services by 2030 is one of the targets (SDG target 3.8) of the United 
Nations' (UN) Sustainable Development Goal 3 (SDG 3) that aims at promoting measures to ensure healthy lives and well-being for all at all ages[14]. The quality of care is complex and encompasses various approaches and dimensions including structure, process and outcomes, each of which requires equal attention in the efforts to improve the quality[15]. The World Health Organization (WHO) defines the quality of care as "the extent to which healthcare services provided to individuals and patient populations improve desired health outcomes. In order to achieve this, health care needs to be safe, effective, timely, efficient, equitable, and people-centered"[16]. Stemming from this definition is the need to account for both clinical and non-clinical indicators when assessing the quality of care. Structural aspects of the quality and health care outcomes including fatalities and users' satisfaction are frequently used to assess the quality of maternity care in SSA $[17,18]$. Process indicators may however more reflect the quality of the care received and provide more information on areas needing improvement[19]. A list of process indicators, suitable for assessing the quality of maternity care in SSA and that combine the measurement of both clinical and non-clinical actions, was recently published[20]. Previous studies using these indicators have reported sub-optimal quality of delivery care[21,22]. While the scarcity of resources is a known obstacle to the delivery of high-cost interventions, it does not always fully explain the non-provision of low cost, yet effective interventions. There is a need for further understanding of the factors that favor or hamper the delivery of low cost and easy to perform interventions during the course of childbirth to inform quality improvement strategies. Previous studies have too-often investigated the quality of Emergency obstetric and Newborn Care (EmONC) only or the quality of EmONC and routine care at a specific point (intrapartum or immediate postpartum only ) during the course of childbirth [27,28,31]and seldomly investigated the quality of routine care along the continuum of care[21,26]. In this study we investigated the 
determinants of the quality of childbirth care using different approaches. The quality of delivery care was assessed using quality indicators that assess the performance of basic clinical and non-clinical actions that are expected at specific points in time (admission, pre-delivery and soon after delivery) during the course of childbirth and the results were reported elsewhere[22]. Here we report on the determinants of the quality of care using typical regression methods along with a structural equation modeling analysis. The later method allows us among other advantages to account for the specificities of the indicators used to measure the quality of care at each point instead of treating them as all equal in weight and to further explore the relationships along the continuum of care where the quality at a later stage may depend on the quality received at previous stages.

\section{Methods}

\section{Data}

The study was conducted in selected health regions of Burkina Faso and Côte d'Ivoire (one in each country) where the research teams have locations and could easily conduct the field activities. Both regions (Central-North in Burkina Faso and Agnéby-Tiassa-Mé in Côte d'Ivoire) have their capital cities located approximately $100 \mathrm{~km}$ away from the respective country capital cities and have similar healthcare delivery systems with on top one regional hospital, followed by district hospitals (six in Burkina and seven in Côte d'Ivoire), each serving a health district comprised of several primary healthcare facilities (PHCFs). A facility based crosssectional study consisting in the direct observation of childbirth practices was conducted in a sample of PHCFs and referral hospitals (regional or district hospital) in each country. We first randomly selected five health districts. The district hospitals of the selected health districts 
along with the regional hospital were systematically included in the study in each country. In

142 the catchment area of each selected health district, up to 15 eligible PHCFs were randomly

143 selected to be included in the study. Eligible PHCFs were those with a minimum average

144 caseload of 1.5 childbirths per day as reported in the health records of the same period in the

145 previous year (during the last quarter of 2017). Details on the sample size calculation were

146 reported elsewhere[22]. In these health facilities, data collectors of medical background

147 (medical students and midwives) and who had undergone a two-day training including in

148 study-room role plays and a field testing of the study tools, were appointed in the delivery

149 room to directly observe and document healthcare providers' adherence to a set of signal

150 functions while caring for pregnant women and their future newborns at four critical points:

151 admission, before the woman starts pushing (pre-delivery), immediately post-partum (soon

152 after delivery up to $\leq 1 \mathrm{~h}$ ), and before discharge from the health facility. Data of the first three

153 pause-points are reported in the current study. Health care providers who were in their

154 qualifying internship period in the health facility were excluded from the observations.

155 Pregnant women aged $<18$ years and those admitted at an advanced stage of the labour (third

156 stage) with frequent ( $\leq 5$ - min apart) and intense uterine contractions that would prevent them

157 from providing valid informed consent were also excluded from the study. The data collection

158 took place from 12 November to 20 December 2018 and lasted for up to five days in each

159 health facility. Observations were conducted every day of the week and at any time without

160 discontinuation, provided an eligible pregnant woman was present in the delivery room. A

161 data collector could observe all or part of the pause-points for each birth event. However,

162 data pertaining to the same critical juncture were fully collected by the same data collector.

163 Thus, once a data collector had initiated the observation for a given pause-point, he/she could

164 get off work only after having filled in all the items pertaining to that pause point. 


\section{Quality indicators}

The quality of delivery care was assessed using a set of 30 signal functions and tracers derived from the WHO Safe Childbirth Check-list (WHO-SCC) [23]complemented through a review of a list of validated and recommended signal functions for SSA[20]. A total of twelve (12) quality indicators (Yes/No) were assessed in each childbirth event at the admission and initial examination stage: the provider washes his/her hands before examination, the provider wears sterile gloves before vaginal examination, the provider asks for historic of vaginal bleedings during the pregnancy, the provider asks for historic of vision blurred, the provider checks the woman HIV status or performs an HIV test where missing, the provider measures the woman blood pressure, the provider takes the woman pulse, the provider measures the temperature, the provider uses a partograph to monitor the labor where indicated, the provider assesses the woman for need of referral to higher level of care, the provider encourages the companion/husband to assist to the childbirth and the provider informs husband/companion to call in case a complication occurs. Eight similar Yes/No indicators were assessed at the predelivery stage (before pushing): sterile gloves readily available, soap and clean water are readily available, providers prepares a prefilled syringe with uterotonics for Active Management of the Third Stage of Labor (AMTSL), clean towel is readily available, sterile blade or scissor is readily available, provider prepares a face mask for neonatal resuscitation, the provider has a suction device readily available, and an assistant birth attendant was identified and ready to intervene if needed.

At the third pause-point, the performance of the following ten (10) signal functions (Yes/No) was assessed: the provider correctly clamps or ties the cord, the provider immediately dries the newborn with clean towel, the provider assesses the mother for vaginal and perineal 
lacerations, the provider assesses the placenta for completeness, the provider takes the mother vital signs (blood pressure, pulse) within 15 min of the delivery, the providers palpates the uterus within 15 min of the delivery, the mother is encouraged to initiate breastfeeding within 1 hour of the delivery, the skin-to-skin contact is initiated within 1 hour of the delivery and the providers informs companion and or woman to call in case of complications.

\section{Determinants of the quality of care}

Quality determinants were categorized into three groups: user, provider and health facility characteristics. Data was collected on the following user's characteristics: maternal age, maternal educational level (none, primary and secondary/tertiary), the number of ever pregnancies that the woman has had in her entire reproductive life and the attendance of at least of four Antenatal Care (ANC) visits during the pregnancy. The cut-off of four ANC visits was used because this was in line with the recommendations per official guidelines in both countries at the time of the data collection. provider's characteristics included the qualification of the health care worker that attends to the childbirth event (midwives, nurses or other auxiliary staffs), the age and gender of the provider, and his total number of years of working experience. Other auxiliary staffs include nurse and midwife' assistants and were found only in Burkina Faso. The following health facility's characteristics were included in the study: facility type (primary health care facility versus referral hospital), the availability of clean running water, the availability of electricity, the health district it belongs to, and the residential location of the health facility (rural versus urban).

\section{Statistical analyses}


We performed three series of analyses. In the descriptive statistics we used proportions and

213 means plus standard deviations to respectively describe qualitative and quantitative variables. Univariate analysis included the use of chi2 test or the independent t-test to compare proportions and means. In the second phase, we carried out negative binomial regressions to identify the determinants of the quality of delivery care for each of the three pause-points and per country. The dependent variable for the negative binomial regression models was a quality score that resulted from the additive combination of the dichotomized quality indicators pertaining to each stage. This quality score had a maximum of 12,8 and 10 for respectively the admission, pre-delivery and soon after delivery phases. The minimum score being 0 for all stages. The negative binomial regression model was preferred to Poisson regression because of its robustness to overdispersion. The analyses performed at this stage were based on complete case analysis. A missing data category was however included in the models of Côte $d^{\prime}$ Ivoire for the variable maternal education that had $13 \%$ of missingness. In the third set of analyses, we used the structural equation modeling (SEM) technique to identify in addition to the determinants of the quality of care, the interrelationships between quality of care in the different phases along the continuum of care. Our model for the continuum of childbirth care includes the three critical points in childbirth care: Initial examination (Admission), Before the woman starts pushing for delivery (Before pushing) and the immediate postpartum (Soon after birth). The quality at each of these points might have been influenced by both health facility and provider's characteristics. The quality at a given stage is also susceptible of having been influenced by the quality at early stages. The SEM technique allows the assessment of the latent variables corresponding to the quality of care at each stage using the observed dichotomized indicators (measurement component of the model) and the effects of the quality at an earlier phase to the quality at a later phase (structural component of the model). 
Groups comparison of countries allowing the structural paths coefficients to vary did not show

a significant difference between the two models and we finally retained a unique SEM model for both countries. Root Mean Square Error of approximation and Comparative Fit Index were used to check the overall fit of the final SEM model. The Root Mean Square Error of approximation (RMSEA) of 0.06 indicated a close to perfect goodness-of-fit. Traditionally, RMSEA below 0.08 shows a satisfactory fit and RMSEA below 0.05 is a perfect fit. Most of the observed indicators were significant at $p<0.05$. [24]. All the analyses were performed using Stata 15.1 and significance was considered if $p<0.05$. Because data were clustered within health facilities, we used robust standard errors.

\section{Results}

\section{Background characteristics}

A total of 532 and 627 pregnant women were included in the admission phase of the study respectively in Burkina Faso and Côte d'Ivoire. Once included in the study (pause-point I), a woman and thereafter her newborn were observed through the subsequent pause-points (II and III) unless they were referred to another health facility or transferred to a different service.

The mean age of women was 25 years in Burkina and 26.5 years in Côte d'Ivoire $(p<0.001)$. The vast majority $(87.63 \%)$ of the childbirth events were attended to by midwives in Côte $d^{\prime}$ Ivoire and that proportion mounts to just more than half $(57.99 \%)$ in Burkina Faso $(p<0.001)$. The providers' mean years of working experience was greater in Côte d'Ivoire as compared to Burkina Faso. Details information of the characteristics of the women, providers and health facilities are presented in Table1.

Table 1: Backgrounds characteristics of study populations 


\begin{tabular}{|c|c|c|c|}
\hline & $\begin{array}{l}\text { Burkina Faso } \mathbf{n}(\%) \\
\mathrm{N}=532\end{array}$ & $\begin{array}{l}\text { Côte d'Ivoire n (\%) } \\
N=627\end{array}$ & $\begin{array}{c}\text { P-value } \\
\text { (Chi2 or t-test) }\end{array}$ \\
\hline \multicolumn{4}{|c|}{ User's characteristics } \\
\hline Maternal age: mean (sd) & $25.08(6.08)$ & $26.47(6.33)$ & $<0.001$ \\
\hline \multicolumn{4}{|l|}{ Maternal education } \\
\hline None & $432(85.48)$ & $309(53.26)$ & $<0.001$ \\
\hline Primary & $58(8.78)$ & $181(26.26)$ & \\
\hline Secondary/tertiary & $42(5.74)$ & $98(13.16)$ & \\
\hline Missing & - & $39(7.31)$ & \\
\hline Number of ever pregnancies: mean (sd) & $1.10(0.84)$ & $1.17(0.75)$ & 0.147 \\
\hline Four ANC visits-Yes & $309(57.45)$ & $328(54.30)$ & 0.402 \\
\hline \multicolumn{4}{|c|}{ Provider's characteristics } \\
\hline \multicolumn{4}{|l|}{ Qualification } \\
\hline Midwives & 347 (57.99) & $575(87.63)$ & $<0.001$ \\
\hline Nurses & $56(13.36)$ & $52(12.37)$ & \\
\hline Other auxiliary staffs & $129(28.65)$ & - & \\
\hline \multicolumn{4}{|l|}{ Gender } \\
\hline Male & $154(32.59)$ & $42(10.21)$ & $<0.001$ \\
\hline Female & $378(67.41)$ & $585(89.79)$ & \\
\hline Provider's age: mean (sd) & $33.64(4.55)$ & $37.57(4.82)$ & $<0.001$ \\
\hline Years of working experience & $4.32(4.18)$ & $6.32(5.09)$ & $<0.001$ \\
\hline \multicolumn{4}{|c|}{ Facility's characteristics } \\
\hline Urban location of the health facility & $141(9.97)$ & $284(29.14)$ & $<0.001$ \\
\hline Rural location of the health facility & $391(90.03)$ & $343(70.86)$ & $<0.001$ \\
\hline Facility has clean water (pipe)-Yes & $291(46.64)$ & $420(58.96)$ & 0.001 \\
\hline \multicolumn{4}{|l|}{ Health districts } \\
\hline Kaya/Agboville & $101(20.59)$ & $118(21.86)$ & \\
\hline Boulsa/Akoupé & 109 (20.59) & 135 (10.99) & \\
\hline Kongoussi/Tiassalé & $118(22.05)$ & $121(21.86)$ & \\
\hline Barsalogho/ALEPE & $102(17.66)$ & $120(21.86)$ & \\
\hline Tougouri/Adzopé & $102(19.12)$ & $133(23.42)$ & \\
\hline
\end{tabular}


The qualification of the provider along with his age and gender showed significant association in multivariable analysis with the quality of care at admission. After adjusting for other factors, nurses and auxiliary staffs had lesser quality rates (IRR=0.81 - 95\% $\mathrm{Cl}(0.72-0.90) ; p<0.001$ and IRR $=0.88-95 \% \mathrm{Cl}(0.80-0.96) ; \mathrm{p}<0.01$, respectively) at admission as compared to midwives.

The quality at admission was also lesser in female provider (IRR=0.89-95\% $\mathrm{Cl}(0.82-0.96)$; $\mathrm{p}<0.01)$ and greater as the provider's age increases $(\mathrm{IRR}=1.01-95 \% \mathrm{Cl}(1.01-1.02) ; \mathrm{p}<0.01)$. The Quality of pre-delivery showed association with facility's characteristics. Referral hospitals had higher quality of pre-delivery care $(\mathrm{IRR}=1.02-95 \% \mathrm{Cl}(1.01-1.18) ; \mathrm{p}<0.05)$ and it was lower in rural health facilities (IRR=0.92-95\% $\mathrm{Cl}(0.86-0.99) ; \mathrm{p}<0.05)$. The quality of immediate postpartum care was positively associated with the age of the provider (IRR=1.01 $95 \% \mathrm{Cl}(1.00-1.02) ; \mathrm{p}<0.01)$.

\section{Côte d'Ivoire}

There were important differences in quality of care at both stages between health districts.

Referral hospitals had higher quality of pre-delivery care (IRR=1.10 - 95\% CI(1.01-1.20); $\mathrm{p}<0.05)$ and lower quality of immediate postpartum care $(\mathrm{IRR}=0.84(0.77-0.93)$ as compared to primary health care facilities. Providers' years of working experience was positively correlated with the quality of immediate post-partum care $(\mathrm{IRR}=1.01-95 \% \mathrm{Cl}(1.00-1.02)$; $\mathrm{p}<0.05)$. The crude and adjusted incidence rate ratios of the quality of care at all three stages in both Burkina Faso and Côte d'Ivoire are presented in table 2.

Insert table 2 here 
The figure 1 presents the standardized parameter estimates for quality of care at the three

291 phases. Two indicators had strong loadings on the quality of care at the admission stage: the

292 provider encourages the companion to assist to the delivery $(\beta=0.62 ; p<0.001)$ and the

293 provider measures the woman temperature $(\beta=0.66 ; p<0.001)$. The indicators with

294 higher loadings on the quality of pre-delivery care were the readily availability of a suction

295 device $(\beta=0.71 ; p<0.001)$ and the availability of a face mask for neonatal resuscitation

$296(\beta=0.64 ; p<0.001)$. The two indicators with the higher loadings on the quality of care at

297 the immediate postpartum stage were respectively the early initiation of skin-to-skin contact

$298(\beta=0.77 ; p<0.001)$ and the early initiation of breastfeeding $(\beta=0.66 ; p<0.001)$. The

299 results of the measurement part of the SEM model are presented in table 3.

300 Table 3: standardized parameter estimates of the measurement indicators of the SEM model

\begin{tabular}{|c|c|c|c|}
\hline Codes & Explanations (labels) & $\begin{array}{l}\text { Standardized } \\
\text { parameter } \\
\text { estimate (Se) }\end{array}$ & t-value \\
\hline Admission & Quality of initial assessment & & \\
\hline Wshd & Washes his/her hands before examination & $0.42(0.04)$ & $11.56 * * *$ \\
\hline Vgbld & Asks for vaginal bleedings & $0.47(0.03)$ & $13.64 * * *$ \\
\hline Vblur & Asks for vision blurred & $0.40(0.04)$ & $11.22 * * *$ \\
\hline bldp & Measures blood pressure & $0.25(0.04)$ & $6.85^{* * *}$ \\
\hline part & Uses partograph where indicated & $0.52(0.03)$ & $15.68 * * *$ \\
\hline Temp & Takes temperature & $0.66(0.03)$ & $18.69 * * *$ \\
\hline P_attd1 & Companion encouraged to assist to childbirth & $0.62(0.05)$ & $13.06 * * *$ \\
\hline P_call1 & Informs companion/woman to call if complications & $0.41(0.03)$ & $13.50 * * *$ \\
\hline Before_pushing & Before pushing or before caesarian section & & \\
\hline q75a & Sterile gloves readily available & $0.08(0.04)$ & $2.38 * *$ \\
\hline$q 75 c$ & Soap and clean water readily available & $-0.16(0.03)$ & $-4.87 * * *$ \\
\hline q76b & Sterile blade or scissor readily available & $0.26(0.04)$ & $7.52 * * *$ \\
\hline mask & Face mask readily available & $0.64(0.04)$ & $14.82 * * *$ \\
\hline asp & Suction device readily available & $0.71(0.05)$ & $14.94 * * *$ \\
\hline
\end{tabular}

Soon_after_birth Immediate postpartum (within one hour) 


\begin{tabular}{llll}
\hline q83r & Clamps or ties cord correctly & $0.38(0.03)$ & $11.63^{* * *}$ \\
q84r & Immediately dries the baby with clean towel & $0.19(0.04)$ & $5.16^{* * *}$ \\
placenta & Assesses for placenta completeness & $0.40(0.03)$ & $13.09 * *$ \\
q90r & Takes mother vital signs within 15 minutes after & $0.41(0.06)$ & $7.09^{* * *}$ \\
q91r & Palpates uterus within 15 minutes after birth & $0.60(0.06)$ & $10.83^{* * *}$ \\
q95r & Initiates breastfeeding within 1 hour & $0.66(0.02)$ & $26.16^{* * *}$ \\
q96r & Skin-to-skin contact initiated within 1 hour & $0.77(0.02)$ & $31.25^{* * *}$ \\
q97r & Informs companion/woman to call if complications & $0.14(0.03)$ & $4.62 * * *$ \\
\hline Provider & Provider's indicators & & \\
\hline q53_b & Age of the provider & $0.98(0.00)$ & $1144.20^{* * *}$ \\
q53_c & Years of working experience of the provider & $0.73(0.01)$ & $49.03 * * *$ \\
attendant & Qualification of the provider & $-0.07(0.03)$ & $-2.30^{*}$ \\
\hline Facility & Health facility indicators & \\
\hline q3 & Health district of the facility & $0.94(0.002)$ & $375.30^{* * *}$ \\
q7 & The health facility has electricity & $0.05(0.03)$ & 1.52 \\
q10 & Hands washing devices/facilities available & $-0.27(0.03)$ & $-9.50 * * *$ \\
\hline 301 & $*$ p & &
\end{tabular}

$301 \quad * p<0.05 .{ }^{* *} p<0.01 \quad * * * p<0.001$

302

303 The results of the structural part of the SEM model are presented in table 4. The structural

304 path relationship from facility characteristic latent (Facility) to initial examination latent

305 (Admission, $(\beta=-0.66 ; p<0.001))$ and to pre-delivery care latent (Before_Pushing, $(\beta=$

$306-0.73 ; p<0.001)$ are negative and statistically significant. On the other hand, the structural

307 path relationship from facility characteristic latent (Facility) to immediate post-partum latent

308 (Soon_after_birth, $\beta=0.05 ; p=0.55$ ) was positive and not statistically significant.

309 Concerning the structural path relationships from the provider latent, the path relationship to

310 initial examination latent (Admission, $\beta=0.11 ; p<0.001$ ) and to the to pre-delivery care

311 latent (Before_Pushing, $(\beta=-0.10 ; p<0.01)$ were significant. Along the continuum of

312 care, the quality of care at the admission (Admission, $\beta=0.48 ; p<0.001$ ) and pre-delivery

313 (Admission, $\beta=0.29 ; p<0.001$ ) stages have positive and statistically significant association

314 with the quality of care at immediate post-partum stage. The quality of care at initial 
assessment, in contrast, had a negative and non-statistically significant association

(Admission, $\beta=-0.07 ; p=0.18$ ) with the quality of pre-delivery care.

Table 4: Standardized estimates of the paths relationships of the quality of care along the continuum.

\begin{tabular}{|c|c|c|}
\hline & $\begin{array}{c}\text { Standardized coefficient } \\
\text { (std error) }\end{array}$ & t-value \\
\hline \multicolumn{3}{|l|}{ PATHS } \\
\hline Provider $\longrightarrow->$ Admission & $0.11(0.04)$ & $3.58 * * *$ \\
\hline Provider $\longrightarrow \longrightarrow$ Before_pushing & $-0.10(0.04)$ & $-2.89 * *$ \\
\hline Provider $-\longrightarrow$ Soon_after_birth & $0.05(0.03)$ & 1.40 \\
\hline Facility $\longrightarrow \longrightarrow$ Admission & $-0.66(0.03)$ & $-21.40 * * *$ \\
\hline Facility - > Before_pushing & $-0.73(0.06)$ & $-11.70 * * *$ \\
\hline Facility $\longrightarrow \longrightarrow$ Soon_after_birth & $0.05(0.09)$ & 0.59 \\
\hline Admission $\longrightarrow \longrightarrow$ Before_pushing & $-0.07(0.05)$ & -1.33 \\
\hline Admission $\longrightarrow \longrightarrow$ Soon_after_birth & $0.48(0.06)$ & $3.48 * * *$ \\
\hline Before_Pushing $\longrightarrow \longrightarrow$ Soon_after_birth & $0.29(0.08)$ & $4.58 * * *$ \\
\hline
\end{tabular}

\section{Discussion}

All women and their newborns should receive adequate care during the intrapartum and immediate postpartum periods to advert perinatal mortality. With the increased recognition that health facility utilization for delivery does not always equate with the receipt of a quality care[9], there are increasing initiatives aiming to measure the quality of care received by the dyad mother and newborn during the course of in-facilities childbirths and its determinants[25-29]. Because the quality of care has several dimensions, studies have used different approaches and quality outcomes including facilities readiness, outcomes of care and users' satisfaction. More studies using process indicators are however still needed as they directly relate to the process of care and are more likely to provide insights into the areas needing improvement[19,30]. Because obstetric complications are unpredictable and will occur in a relative few proportion of women, the quality of routine care does matter. Routine 
care is what is received by the vast majority of women and their newborns and its quality is

335 critical in preventing complications[32]. In this study we used a list of validated process indicators for SSA to assess the determinants of the quality of routine care in two LMICs[20]. In our results, the quality of care at both stages tend to be lower for nurses and auxiliary staffs as compared to midwives. The results were however not statistically significant in Côte d'Ivoire. Similar results have been reported previously and may be the reflect of the differences in midwifery skills between midwives and other cadre of health workers who are not in first intention trained to provide childbirth care[21,28]. The results were not significant in Côte d'Ivoire probably because of the distribution of the variable qualification of the provider in our data (around $90 \%$ were midwives) that may have hampered the investigation of its full effects on the quality of care. The quality of immediate postpartum care significantly increases with provider's years of working experience in Côte d'Ivoire data. More experienced health workers are also more likely to have benefited from quality improvement initiatives (in-service trainings, supportive supervisions etc.) that have reinforced their skills and competences[31]. Worthy of note were the results on the type of facility in our study. While the quality of pre-delivery care was significantly higher in referral hospitals as compared to primary health care facilities in both countries, there was either no difference in the quality of initial assessment and immediate postpartum care, or the difference was in favor of primary health care facilities (postpartum care in Côte d'Ivoire). The difference in performance at the different stages between referral and primary health facilities is probably the reflect of the difference between the inputs used to define quality care at different stages. Indeed, the quality indicators at the pre-delivery stage are more focused on the readily availability for use by the health care providers of childbirth consumables, while the indicators at the initial examination and postpartum stages are rather more focused on the assessment of the actual 
performance of clinical actions or the quality of inter-personal communication. The SEM analysis showed that while health facility's characteristics and provider's characteristics were significant predictors of the quality of care at both Admission and pre-pushing stages, they were not associated with the quality of immediate post-partum care which was positively correlated with both the quality at Admission and pre-pushing stages. In both countries, quality improvement strategies have recently put emphasis on training of maternity care providers. The strong and significant correlations between health facilities and the quality of childbirth care at admission and pre-delivery stages in our findings, underscore the importance of enabling environment to the quality of care and suggest that quality improvement interventions should not only target health care providers. The relationship between quality at pre-delivery stage and the quality of care at immediate postpartum stage was positive and significant as was reported in a previous similar study[21]. Despite the difference between the quality inputs for the different stages, these inputs are provided by the same teams of health workers working in the same working environments making the correlation between the quality at a given phase and the quality at the next phase, obvious and relevant to account for in the regression models[33].

\section{Study strengths and limitations}

The assessment of the quality of care in our study was based on a list of process indicators that have been validated for settings similar to ours. We used different analytical approaches that have among other the advantage of acknowledging the multidimensionality of the quality of care by allowing it to vary across different points in time along the continuum of care instead of treating the quality as a unique score with no distinction between initial 
examination, pre-delivery and immediate postpartum periods[26]. The quality determinants were investigated for each period separately and altogether for all periods.

Because of the direct observation of the practices, we cannot rule out the Hawthorne effect, that is despite mitigating measures, some provider might have modified their practices under observation. Data were collected by eight data collectors in each country and are thus subject to an inter-rater reliability bias even though they were trained to standardize the processes.

Finally, our study did not include data on some quality improvement initiatives that were found relevant in previous studies: existence of quality improvement guidelines in the health facility, in-service trainings of providers and supportive supervisions received.

\section{Conclusion}

Ensuring that all women and newborns have access to quality care along the continuum of childbirth care is critical for ending preventable perinatal deaths. Both facility and provider levels quality improvement strategies are needed to impact the whole continuum of care. Stage specific inputs are needed to improve the quality of delivery care along the continuum and the quality of the delivery care at an earlier stage is correlated to the quality at a subsequent stage.

\section{List of abbreviations}

AMSTL: Active Management of the Third Stage of Labor

ANC: Antenatal Care visit

EBP: Essential Best Practice

EmONC: Emregency Obstetric and Newborn Care

HRP: Human Reproduction Program 
IRR: Incidence Rate Ratio

407 LMIC: Low-Middle Income Countries

408

PHCF: Primary Health Care Facility

409 SCC: Safe Childbirth Checklist

410 SDG: Sustainable Development Goals

411 SEM: Structural Equation Modeling

412 SSA: Sub-Saharan Africa

413 RMSEA: Root Mean Square Error of Approximation

414 UN: United Nations

WHO: World Health Organization

\section{Declarations}

The research protocol obtained ethical approvals from the national ethics review committees of Burkina Faso (reference number 2017-4-043) and Côte d'Ivoire (161-18/MSHP/CNE SVS$\mathrm{Kp}$ ). It was also approved by the ethics review committee of the WHO (protocol ID ERC.0002951). Written informed consent was obtained from all study participants. To the best of our knowledge, all the methods were performed in accordance with relevant guidelines 425 and regulations.

427 Not applicable. 
The datasets used in the current study are available from the corresponding author on reasonable request

433 The authors declare that they have no competing interests

\section{Funding}

\section{7}

The study was funded by WHO/HRP. The funders have no role in the design, the conduct, the analysis and interpretation of the study results.

\section{Authors' contributions}

All authors meet the criteria recommended by the International Committee of Medical Journal

Editors (ICMJE). All authors made substantial contributions to conception and design, acquisition of data or analysis and interpretation of data. SK, TM, RKK and MLA conceived the study design. TM analyzed the data and proposed the first draft of the paper. BIM and AD provide insights into the data analysis and interpretation. SK, MLA, RKK, MWY, BIM, and AD revised and contributed to the successive drafts and have all approved the final version of the paper.

\section{Acknowledgment}

448 We are grateful to the other colleagues from the check-list project in Côte d'Ivoire for their 449 contribution to the global project that provided data for the current study: Akoua TanoKamelan, Aminata Soltié Koné-Coulibaly, Fatou B Sissoko. 
452 Figure 1: This figure depicts the structural equation model for the analysis of the determinants

453 of the quality of childbirth care along the continuum. The measurement component of the 454 model has two parts: the latent endogenous quality variables (Admission, before pushing, 455 Soon after birth) and their respective observed indicators variables and the latent exogenous 456 variables: provider and facility variables along equally with their observed indicator variables. 457 The structural component is composed of the relationships between the latent exogenous and 458 latent endogenous variables. The standardized coefficients are presented on the path 


\section{References}

461

462 1. United Nations. Millennium Development Goals Report 2015. [Internet]. New York, NY: United

463

Nations;

Available

from:

464

https://www.un.org/millenniumgoals/2015_MDG_Report/pdf/MDG\%202015\%20rev\%20(July\%201).

465 pdf

466

2. World Health Organization. Making pregnancy safer the critical role of the skilled attendant: a

467 joint statement by WHO, ICM and FIGO. Geneva: World health organization; 2004.

3. Ronsmans C, Graham WJ, Lancet Maternal Survival Series steering group. Maternal mortality: who, when, where, and why. Lancet. 2006 Sep 30;368(9542):1189-200.

4. Kinney MV, Kerber KJ, Black RE, Cohen B, Nkrumah F, Coovadia H, Nampala PM, Lawn JE,

Science in Action: Saving the lives of Africa's Mothers, Newborns, and Children working group, Axelson

H, Bergh A-M, Chopra M, Diab R, Friberg I, Odubanjo O, Walker N, Weissman E. Sub-Saharan Africa's mothers, newborns, and children: where and why do they die? PLoS Med. 2010 Jun;7(6):e1000294. Africa: successes, challenges, and implications for the 2030 development agenda. BMC Public Health. 2018 Dec;18(1):765.

6. Udo IE, Doctor HV. Trends in Health Facility Births in sub-Saharan Africa: An Analysis of Lessons Learned under the Millennium Development Goal Framework. Afr J Reprod Health [Internet]. 2017

from:

480 https://www.ajrh.info/index.php/ajrh/article/view/175

481 7. Randive B, Diwan V, De Costa A. India's Conditional Cash Transfer Programme (the JSY) to 482 Promote Institutional Birth: Is There an Association between Institutional Birth Proportion and 483 Maternal Mortality? Baradaran HR, editor. PLoS ONE. 2013 Jun 27;8(6):e67452.

484 8. van den Broek N, Graham W. Quality of care for maternal and newborn health: the neglected 
485

486

487

488

489

490

491

492

493

494

495

496

497

498

499

500

501

502

503

504

505

506

507

508

509

510

agenda: Quality of care for maternal and newborn health. BJOG Int J Obstet Gynaecol. 2009 Oct;116:18-21.

9. Campbell OMR, Calvert C, Testa A, Strehlow M, Benova L, Keyes E, Donnay F, Macleod D, Gabrysch S, Rong L, Ronsmans C, Sadruddin S, Koblinsky M, Bailey P. The scale, scope, coverage, and capability of childbirth care. Lancet Lond Engl. 2016 29;388(10056):2193-208.

10. Gabrysch S, Nesbitt RC, Schoeps A, Hurt L, Soremekun S, Edmond K, Manu A, Lohela TJ, Danso S, Tomlin K, Kirkwood B, Campbell OMR. Does facility birth reduce maternal and perinatal mortality in Brong Ahafo, Ghana? A secondary analysis using data on 119244 pregnancies from two clusterrandomised controlled trials. Lancet Glob Health. 2019;7(8):e1074-87.

11. Moyer CA, Adongo PB, Aborigo RA, Hodgson A, Engmann CM. "They treat you like you are not a human being": maltreatment during labour and delivery in rural northern Ghana. Midwifery. 2014 Feb;30(2):262-8.

12. Kyomuhendo GB. Low Use of Rural Maternity Services in Uganda: Impact of Women's Status, Traditional Beliefs and Limited Resources. Reprod Health Matters. 2003 Jan;11(21):16-26.

13. Bohren MA, Vogel JP, Hunter EC, Lutsiv O, Makh SK, Souza JP, Aguiar C, Saraiva Coneglian F, Diniz ALA, Tunçalp Ö, Javadi D, Oladapo OT, Khosla R, Hindin MJ, Gülmezoglu AM. The Mistreatment of Women during Childbirth in Health Facilities Globally: A Mixed-Methods Systematic Review. Jewkes R, editor. PLOS Med. 2015 Jun 30;12(6):e1001847.

14. United Nations. Transforming our world: the 2030 Agenda for Sustainable Development | Department of Economic and Social Affairs [Internet]. [cited 2020 Aug 20]. Available from: https://sdgs.un.org/2030agenda

15. Donabedian A. The quality of care. How can it be assessed? JAMA. 1988 Sep 23;260(12):17438.

16. Tunçalp ö, Were W, MacLennan C, Oladapo O, Gülmezoglu A, Bahl R, Daelmans B, Mathai M, Say L, Kristensen F, Temmerman M, Bustreo F. Quality of care for pregnant women and newborns-the WHO vision. BJOG Int J Obstet Gynaecol. 2015 Jul;122(8):1045-9. 
511 17. Admasu K, Haile-Mariam A, Bailey P. Indicators for availability, utilization, and quality of 512 emergency obstetric care in Ethiopia, 2008. Int J Gynecol Obstet. 2011 Oct;115(1):101-5.

513 18. Wilunda C, Oyerinde K, Putoto G, Lochoro P, Dall'Oglio G, Manenti F, Segafredo G, Atzori A, 514 Criel B, Panza A, Quaglio G. Availability, utilisation and quality of maternal and neonatal health care services in Karamoja region, Uganda: a health facility-based survey. Reprod Health [Internet]. 2015 Dec [cited 2017 Dec 18];12(1). Available from: http://reproductive-health-

517

518

519

520

521 journal.biomedcentral.com/articles/10.1186/s12978-015-0018-7

19. Campbell OM, Graham WJ, group LMSS steering, others. Strategies for reducing maternal mortality: getting on with what works. The lancet. 2006;368(9543):1284-1299.

20. Tripathi V, Stanton C, Strobino D, Bartlett L. Development and Validation of an Index to Measure the Quality of Facility-Based Labor and Delivery Care Processes in Sub-Saharan Africa. Duan T, editor. PLOS ONE. 2015 Jun 24;10(6):e0129491.

21. Owili PO, Muga MA, Mendez BR, Chen B. Quality of maternity care and its determinants along the continuum in Kenya: A structural equation modeling analysis. Moyer CA, editor. PLOS ONE. 2017 May 16;12(5):e0177756.

22. Millogo T, Agbre-Yace ML, Kourouma RK, Yaméogo WME, Tano-Kamelan A, Sissoko FB, KonéCoulibaly AS, Thorson A, Kouanda S. Quality of maternal and newborn care in limited-resource settings: a facility-based cross-sectional study in Burkina Faso and Côte d'Ivoire. BMJ Open. 2020 Jun;10(6):e036121.

23. Spector JM, Lashoher A, Agrawal P, Lemer C, Dziekan G, Bahl R, Mathai M, Merialdi M, Berry W, Gawande AA. Designing the WHO Safe Childbirth Checklist program to improve quality of care at childbirth. Int J Gynecol Obstet. 2013 Aug;122(2):164-8.

24. $\mathrm{Hu}$ L, Bentler PM. Cutoff criteria for fit indexes in covariance structure analysis: Conventional criteria versus new alternatives. Struct Equ Model Multidiscip J. 1999 Jan;6(1):1-55.

25. Saaka M, Ali F, Vuu F. Prevalence and determinants of essential newborn care practices in the Lawra District of Ghana. BMC Pediatr. 2018 24;18(1):173. 
26. Diamond-Smith N, Sudhinaraset M, Montagu D. Clinical and perceived quality of care for

538 maternal, neonatal and antenatal care in Kenya and Namibia: the service provision assessment. Reprod 539 Health. 2016 Aug 11;13(1):92.

27. Kozuki N, Oseni L, Mtimuni A, Sethi R, Rashidi T, Kachale F, Rawlins B, Gupta S. Health facility service availability and readiness for intrapartum and immediate postpartum care in Malawi: A crosssectional survey. PloS One. 2017;12(3):e0172492.

543 28. Benova L, Owolabi O, Radovich E, Wong KLM, Macleod D, Langlois EV, Campbell OMR. 544 Provision of postpartum care to women giving birth in health facilities in sub-Saharan Africa: A crosssectional study using Demographic and Health Survey data from 33 countries. PLoS Med. 2019;16(10):e1002943.

29. Weldearegay HG, Kahsay AB, Medhanyie AA, Godefay H, Petrucka P. Quality of and barriers to routine childbirth care signal functions in primary level facilities of Tigray, Northern Ethiopia: Mixed method study. PloS One. 2020;15(6):e0234318.

30. Marchant T, Tilley-Gyado RD, Tessema T, Singh K, Gautham M, Umar N, Berhanu D, Cousens S, Armstrong Schellenberg JR. Adding Content to Contacts: Measurement of High Quality Contacts for 552 Maternal and Newborn Health in Ethiopia, North East Nigeria, and Uttar Pradesh, India. Roy JK, editor. PLOS ONE. 2015 May 22;10(5):e0126840.

31. Fisseha G, Berhane Y, Worku A. Quality of intrapartum and newborn care in Tigray, Northern Ethiopia. BMC Pregnancy Childbirth. 2019 Jan 18;19(1):37.

32. WORLD HEALTH ORGANIZATION. Who recommendations on intrapartum care for a positive childbirth experience. Place of publication not identified: WORLD HEALTH ORGANIZATION; 2018. 1995 Jul 1;10(3):339-41. 
Table 2: Crude and adjusted incidence rate ratios for quality of care at admission, pre-delivery and immediate post-partum and per country

\begin{tabular}{|c|c|c|c|c|c|c|}
\hline & \multicolumn{3}{|c|}{ Crude Incidence rate ratio (IRR, 95\% confidence interval) } & \multicolumn{3}{|c|}{ Adjusted Incidence rate ratio (IRR, 95\% confidence interval) } \\
\hline \multicolumn{7}{|c|}{ Burkina Faso } \\
\hline Variables & Admission $(n=532)$ & Before pushing & Soon after birth & Admission & Before pushing & Soon after birth \\
\hline \multicolumn{7}{|l|}{ User characteristics } \\
\hline Maternal age & $0.99(0.99-1.01)$ & 0.99(0.99-1.00) & 0.99(0.99-1.00) & $0.99(0.98-1.00)$ & $0.99(0.99-1.01)$ & $0.99(0.99-1.00)$ \\
\hline \multicolumn{7}{|l|}{ Maternal education (ref=None) } \\
\hline Primary & 1.06(0.94-1.19) & $0.93(0.86-1.01)$ & $0.97(0.90-1.05)$ & 1.04(0.93-1.16) & $0.93(0.86-1.02)$ & $0.95(0.89-1.02)$ \\
\hline Secondary/tertiary & $1.07(0.96-1.18)$ & 1.02(0.93-1.13) & $1.01(0.91-1.11)$ & $0.92(0.81-1.04)$ & $0.98(0.89-1.09)$ & $0.95(0.86-1.04)$ \\
\hline Number of ever pregnancies & $0.98(0.94-1.03)$ & 0.99(0.97-1.02) & $0.97(0.94-0.99)$ & $1.00(0.94-1.07)$ & $0.99(0.96-1.03)$ & $0.99(0.94-1.03)$ \\
\hline Four ANC visits (ref=No) & $1.02(0.95-1.10)$ & $1.01(0.96-1.06)$ & $1.01(0.96-1.06)$ & $1.00(0.94-1.07)$ & $1.02(0.98-1.06)$ & $1.09(0.97-1.05)$ \\
\hline \multicolumn{7}{|l|}{ Provider characteristics } \\
\hline \multicolumn{7}{|l|}{ Qualification (ref= midwives) } \\
\hline Nurses & $0.91(0.81-1.03)$ & $1.04(0.97-1.11)$ & $0.98(0.92-1.04)$ & $0.81(0.72-0.90) * * *$ & $0.99(0.93-1.05)$ & $0.96(0.91-1.03)$ \\
\hline Other auxiliary staffs & $0.94(0.86-1.03)$ & $0.97(0.92-1.02)$ & $0.97(0.91-1.03)$ & $0.88(0.80-0.96)^{* *}$ & $0.96(0.91-0.99)^{*}$ & $0.95(0.89-1.00)$ \\
\hline Gender (ref=Male) & $0.94(0.87-1.07)$ & $0.93(0.90-0.98)^{* *}$ & $0.96(0.92-1.01)$ & $0.89(0.82-0.96)^{* *}$ & $0.99(0.94-1.04)$ & $0.98(0.92-1.03)$ \\
\hline Provider's age & $1.02(1.01-1.03)^{* * *}$ & $1.01(1.00-1.01)^{* *}$ & $1.01(0.99-1.01)$ & $1.01(1.01-1.02) * *$ & $1.00(0.99-1.01)$ & $1.01(1.00-1.02)^{* *}$ \\
\hline Years of working experience & $1.02(1.01-1.02)^{* * *}$ & $1.01(1.00-1.01)^{*}$ & $1.01(1.00-1.01)^{* * *}$ & $1.00(0.99-1.01)$ & $1.00(0.99-1.01)$ & - \\
\hline \multicolumn{7}{|l|}{ Facility characteristics } \\
\hline Referral hospital (ref= PHCF) & $1.11(1.04-1.19)^{* *}$ & $1.15(1.09-1.20)^{* * *}$ & $0.98(0.93-1.04)$ & $1.07(0.96-1.20)$ & $1.02(1.01-1.18)^{*}$ & $0.96(0.90-1.03)$ \\
\hline Rural location (ref= urban) & $0.88(0.81-0.95)^{* *}$ & $0.91(0.86-0.97)^{* *}$ & $0.90(0.86-0.95)^{* * *}$ & $1.02(0.90-1.16)$ & $0.92(0.86-0.99)^{*}$ & $0.97(0.91-1.02)$ \\
\hline $\begin{array}{l}\text { Full staff on duty at childbirth } \\
\text { (ref= No) }\end{array}$ & $1.06(0.99-1.15)$ & $1.01(0.96-1.06)$ & $1.02(0.97-1.08)$ & $1.02(0.95-1.10)$ & $1.02(0.97-1.07)$ & $1.02(0.98-1.08)$ \\
\hline Facility has clean water (pipe) & $1.12(1.05-1.21)^{* *}$ & $0.93(0.89-0.97)^{* *}$ & $0.99(0.95-1.04)$ & $1.03(0.95-1.11)$ & $0.95(0.92-0.99)^{*}$ & $0.99(0.94-1.03)$ \\
\hline \multicolumn{7}{|l|}{ Health districts (ref=Kaya) } \\
\hline Boulsa & $0.93(0.84-1.01)$ & $1.13(1.06-1.20)^{* * *}$ & $0.94(0.88-1.01)$ & $0.94(0.85-1.04)$ & $1.14(1.07-1.21)^{* * *}$ & $0.96(0.89-1.04)$ \\
\hline Kongoussi & $0.68(0.61-0.76)^{* * *}$ & $1.06(1.01-1.12)^{*}$ & $0.98(0.94-1.03)$ & $0.66(0.59-0.75)^{* * *}$ & $1.06(0.99-1.12)$ & $0.99(0.93-1.05)$ \\
\hline Barsalogho & $0.76(0.69-0.84)^{* * *}$ & $1.06(0.99-1.14)$ & $0.94(0.89-0.99)^{*}$ & $0.75(0.66-0.85)^{* * *}$ & $1.07(1.00-1.14) *$ & $0.95(0.88-1.02)$ \\
\hline Tougouri & $0.74(0.68-0.81)^{* * *}$ & $0.83(0.77-0.88)^{* * *}$ & $0.79(0.74-0.84)^{* * *}$ & $0.75(0.68-0.83)^{* * *}$ & $0.85(0.79-0.91)^{* * *}$ & $0.81(0.75-0.87)^{* * *}$ \\
\hline \multicolumn{7}{|c|}{ Côte d'Ivoire } \\
\hline
\end{tabular}




\begin{tabular}{|c|c|c|c|c|c|c|}
\hline \multirow[b]{2}{*}{ Variables } & \multicolumn{3}{|c|}{ Crude Incidence rate ratio (IRR, 95\% confidence interval) } & \multicolumn{3}{|c|}{ Adjusted Incidence rate ratio (IRR, 95\% confidence interval) } \\
\hline & Admission $(n=627)$ & Before pushing & Soon after birth & Admission & Before pushing & Soon after birth \\
\hline \multicolumn{7}{|l|}{ User characteristics } \\
\hline Maternal age & $0.99(0.99-1.00)$ & $0.99(0.99-1.00)$ & $0.99(0.99-1.00)$ & $0.99(0.99-1.00)$ & $1.00(0.99-1.01)$ & $0.99(0.99-1.00)$ \\
\hline \multicolumn{7}{|l|}{ Maternal education (ref=None) } \\
\hline Primary & $0.96(0.88-1.04)$ & $0.98(0.92-1.04)$ & $0.94(0.89-0.99)^{*}$ & $1.00(0.94-1.08)$ & $0.98(0.92-1.04)$ & $0.96(0.91-1.01)$ \\
\hline Secondary/tertiary & $0.96(0.87-1.06)$ & $1.04(0.95-1.13)$ & $0.88(0.82-0.96)^{*}$ & $1.02(0.92-1.15)$ & $1.10(1.01-1.21)^{*}$ & $0.96(0.88-1.04)$ \\
\hline Number of ever pregnancies & $0.99(0.94-1.05)$ & $0.99(0.97-1.02)$ & $1.01(0.98-1.05)$ & $1.02(0.97-1.07)$ & $0.95(0.90-0.99)^{*}$ & $1.05(1.00-1.09)^{*}$ \\
\hline Four ANC visits (ref=No) & $1.03(0.95-1.12)$ & $0.99(0.94-1.04)$ & $1.02(0.97-1.07)$ & $1.03(0.96-1.10)$ & $0.95(0.86-1.01)$ & $1.03(0.98-1.08)$ \\
\hline \multicolumn{7}{|l|}{ Provider characteristics } \\
\hline \multicolumn{7}{|l|}{ Qualification (ref= midwives) } \\
\hline Nurses & $0.91(0.79-1.05)$ & $0.92(0.85-0.99)^{*}$ & $0.89(0.82-0.97)^{* *}$ & $0.93(0.77-1.12)$ & $0.94(0.80-1.11)$ & $0.92(0.78-1.08)$ \\
\hline \multicolumn{7}{|l|}{ Other auxiliary staffs } \\
\hline Gender Female(ref=Male) & $1.08(0.91-1.27)$ & $1.12(1.03-1.22)^{*}$ & $1.14(1.03-1.28)^{* *}$ & $1.04(0.83-1.32)$ & $1.18(0.93-1.48)$ & $1.19(0.97-1.47)$ \\
\hline Provider's age & $0.99(0.98-1.00)$ & $1.01(1.00-1.01)^{*}$ & $1.00(0.99-1.01)$ & $1.01(0.99-1.02)$ & $1.00(0.99-1.01)$ & $1.00(0.99-1.01)$ \\
\hline Years of working experience & $0.99(0.98-1.01)$ & $1.01(1.00-1.01)^{* *}$ & $1.00(0.99-1.01)$ & $1.00(0.99-1.01)$ & $1.00(0.99-1.01)$ & $1.01(1.00-1.02)^{*}$ \\
\hline \multicolumn{7}{|c|}{ Facility characteristics } \\
\hline Referral hospital (ref= PHCF) & $0.82(0.74-0.91)^{* * *}$ & $1.10\left(1.04 \_1.15\right)^{* * *}$ & $0.88(0.82-0.94)^{* * *}$ & $0.77(0.68-0.87)$ & $1.10(1.01-1.20) *$ & $0.84(0.77-0.93)^{* * *}$ \\
\hline Rural location (ref= urban) & $0.96(0.87-1.05)$ & $0.99(0.94-1.04)$ & $0.98(0.94-1.03)$ & $1.02(0.96-1.09)$ & $1.05(0.99-1.12)$ & $0.99(0.94-1.06)$ \\
\hline $\begin{array}{l}\text { Full staff on duty at childbirth } \\
\text { (ref= No) }\end{array}$ & $1.04(0.94-1.14)$ & $0.97(0.92-1.03)$ & $0.98(0.94-1.03)$ & $1.02(0.95-1.09)$ & $1.00(0.93-1.07)$ & $1.01(0.94-1.08)$ \\
\hline Facility has clean water (pipe) & $1.05(0.96-1.15)$ & $1.01(0.95-1.06)$ & $0.96(0.91-1.01)$ & $1.05(0.98-1.13)$ & $1.06(0.99-1.13)$ & $1.03(0.97-1.09)$ \\
\hline \multicolumn{7}{|c|}{ Health districts (ref= Adzopé) } \\
\hline Akoupé & $0.85(0.77-0.93)^{* * *}$ & $1.12(1.03-1.22)^{* *}$ & $0.95(0.88-1.03)$ & $0.86(0.78-0.95)^{* *}$ & $1.17(1.07-1.28) * *$ & $0.95(0.87-1.03)$ \\
\hline Alepé & $1.24(1.14-1.35)^{* * *}$ & 1.04(0.94-1.15) & $1.15(1.07-1.24)^{* * *}$ & $1.30(1.18-1.43)^{* * *}$ & $1.11(1.00-1.23)^{*}$ & $1.19(1.11-1.29)^{* * *}$ \\
\hline Tiassalé & $1.03(0.88-1.21)$ & $1.17(1.07-1.28)^{* * *}$ & $1.29(1.19-1.41)^{* * *}$ & $1.06(0.84-1.34)$ & $1.31(1.15-1.49)^{* * *}$ & $1.37(1.20-1.55)^{* * *}$ \\
\hline Agboville & $0.88(0.82-0.96)^{* *}$ & $1.21(1.11-1.31)^{* * *}$ & $1.01(1.01-1.15)^{*}$ & $0.85(0.78-0.94)^{* *}$ & $1.23(1.13 .-1.33)^{* * *}$ & $1.01(0.92-1.10)$ \\
\hline
\end{tabular}




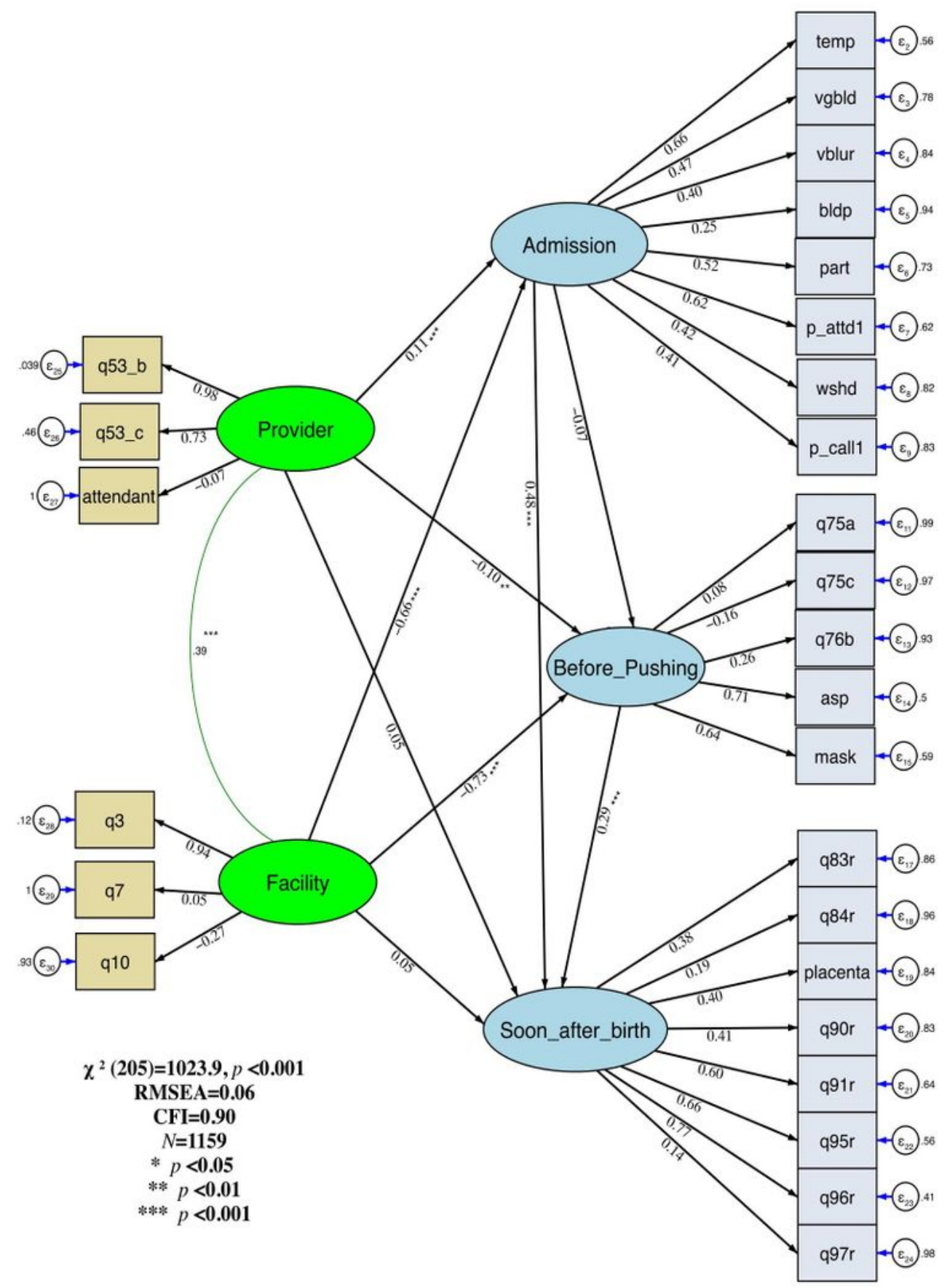

Figure 1

standardized parameter estimates of the quality of care along the continuum of care (see table3 for codes labels and explanations). 